\title{
REENGENHARIA E PROJETO COM APLICAÇÃO DE NOVAS TECNOLOGIAS EM MANDRIS DE BOBINADEIRAS E DESBOBINADEIRAS DE LAMINADORES A QUENTE, A FRIO E LINHAS DE PROCESSO *
}

Fabiano Rodrigues Soares ${ }^{1}$

\begin{abstract}
Resumo
O Mandril é um dos mais importantes componentes da laminação de tiras, pois trabalha diretamente na qualidade do produto, tanto para o cliente interno quanto para o cliente externo. Para atender a demanda do mercado de Siderurgia e Alumínio para a área de laminação a quente, a frio e linhas de processo, temos a necessidade de entender os conceitos existentes e desenvolver novas formas para aumentar a performance do equipamento, resultando em menores gastos com manutenção e um menor número de tempo parado da linha, culminando em lucro para a empresa. Será apresentado neste trabalho tecnologia em reengenharia e projeto de Mandris, aplicando know how adquirido dentro de vários anos de experiência e ainda contando com o apoio tecnológico de nossos colegas da Alemanha com soluções de excelente qualidade para o cliente. Estas soluções podem ser através de novos materiais, novos revestimentos e novos conceitos de trabalho do equipamento.
\end{abstract}

Palavras-chave: Reengenharia; Laminação; Mandril; Bobinadeira.

\section{REENGENERING AND DESIGN WITH APPLICATION OF NEW TECHNOLOGIES IN COILERS AND UNCOILERS MANDRELS TO HOT STRIP MILL, COLD STRIP MILL AND STRIP PROCESSING LINE}

\begin{abstract}
Mandrel is one of the most important components of Strip Mill because deal directly with product quality both for the internal as for external customer. To meet the demand of the Steel and Aluminum market for the Hot Strip Mill, Cold Strip Mill and Strip processing lines, we need to understand existing concepts and develop new ways to increase equipment performance, resulting in lower maintenance costs and a lower number of line stopover, culminating in profit for the company. We will present in this work technology in reengineering and design of Mandrels, applying know how acquired within several years of experience and technological support of our colleagues from Germany with excellent solutions for the customer. These solutions can be made by new materials, new coatings and new concepts of this equipment.
\end{abstract}

Keywords: Reengineering; Rolling Mill; Mandrel; Coiler.

1 Engenharia Mecânica, Engenheiro, Especialista em mandris, Coordenação técnica e Vendas, SMS Group, Belo Horizonte, Minas Gerais, Brasil. 


\section{INTRODUÇÃO}

O Mandril é um dos mais importantes componentes da laminação de tiras, pois trabalha diretamente na qualidade do produto, tanto para o cliente interno quanto para o cliente externo. Atender a demanda do cliente com baixo custo é o constante desafio das empresas que prestam serviço para manutenção dos equipamentos desta área. Com o mercado ditando preços cada vez mais baixos devido à alta concorrência tanto nacional como internacional, precisa-se conhecer os conceitos existentes e novas tecnologias, agregar conhecimento para aplicação da melhor solução, com qualidade, para aumento da performance do equipamento.

\section{MATERIAIS E MÉTODOS}

Este trabalho apresenta tecnologia em reengenharia e projeto de Mandris para as áreas de laminação a quente, a frio e linhas de processo, aplicando know how adquirido dentro de vários anos de experiência e ainda contando com o apoio tecnológico de nossos colegas da Alemanha. Várias soluções podem ser encontradas através do emprego de novos materiais, novos revestimentos e novos conceitos de trabalho do equipamento.

\section{RESULTADOS E DISCUSSÃO}

\subsection{Projetos de mandris no Brasil}

Abaixo apresenta-se uma tabela de mandris projeto SMS instalados hoje no Brasil. Estas são as quantidades de mandris em operação em cada cliente de acordo com a linha de laminação ou processo.

Tabela 1. Distribuição dos mandris SMS no Brasil

\begin{tabular}{|c|c|c|c|c|c|c|c|c|c|c|c|}
\hline Linha & HSM & TCM & RCM & PLTCM & SPM & CGL & CPL & RCL & Sendz. & PL & Total \\
\hline Cliente 1 & 5 & $x$ & $x$ & $x$ & $\mathrm{x}$ & $x$ & $x$ & $x$ & $\mathrm{x}$ & $x$ & 5 \\
\hline Cliente 2 & $x$ & 3 & $x$ & $x$ & 4 & $x$ & 2 & 3 & $x$ & $x$ & 12 \\
\hline Cliente 3 & $x$ & $x$ & $x$ & $x$ & $x$ & $x$ & $x$ & $x$ & 4 & $x$ & 4 \\
\hline Cliente 4 & $\mathrm{x}$ & $\mathrm{x}$ & 6 & $\mathrm{x}$ & $\mathrm{x}$ & $\mathrm{x}$ & $\mathrm{x}$ & $\mathrm{x}$ & $x$ & $x$ & 6 \\
\hline Cliente 5 & $x$ & $x$ & $x$ & $x$ & $x$ & 5 & $x$ & $x$ & $x$ & $x$ & 5 \\
\hline Cliente 6 & $x$ & $x$ & 3 & $x$ & $x$ & 5 & 3 & $x$ & $x$ & 3 & 14 \\
\hline Cliente 7 & 2 & $x$ & 3 & $x$ & $x$ & $x$ & $x$ & 2 & $x$ & $x$ & 7 \\
\hline Cliente 8 & $x$ & $x$ & $\mathrm{x}$ & 5 & $x$ & $x$ & $x$ & 1 & $x$ & $x$ & 6 \\
\hline TOTAL & 7 & 3 & 11 & 5 & 4 & 10 & 5 & 6 & 4 & 3 & 59 \\
\hline
\end{tabular}

${ }^{*}$ Quantidade de mandris por cliente.

\subsubsection{Laminação a quente}

A concepção de Mandril mais usada hoje para bobinadeira de laminadores a quente utiliza um eixo piramidal acionado por cilindro hidráulico e cunhas de expansão com molas que transmitem o deslocamento axial do eixo para um deslocamento radial dos segmentos através das rampas, expandindo ou colapsando o mandril. Para a rotação do mandril tem-se uma conexão por acoplamento diretamente na caixa de 
engrenagens ou uma engrenagem principal fixada no corpo principal do mandril. As figuras 1 e 2 mostram um esquemático geral.

Coiler mandrel details, hydraulic cylinder, Proxicaptor disk and main mandrel bearing

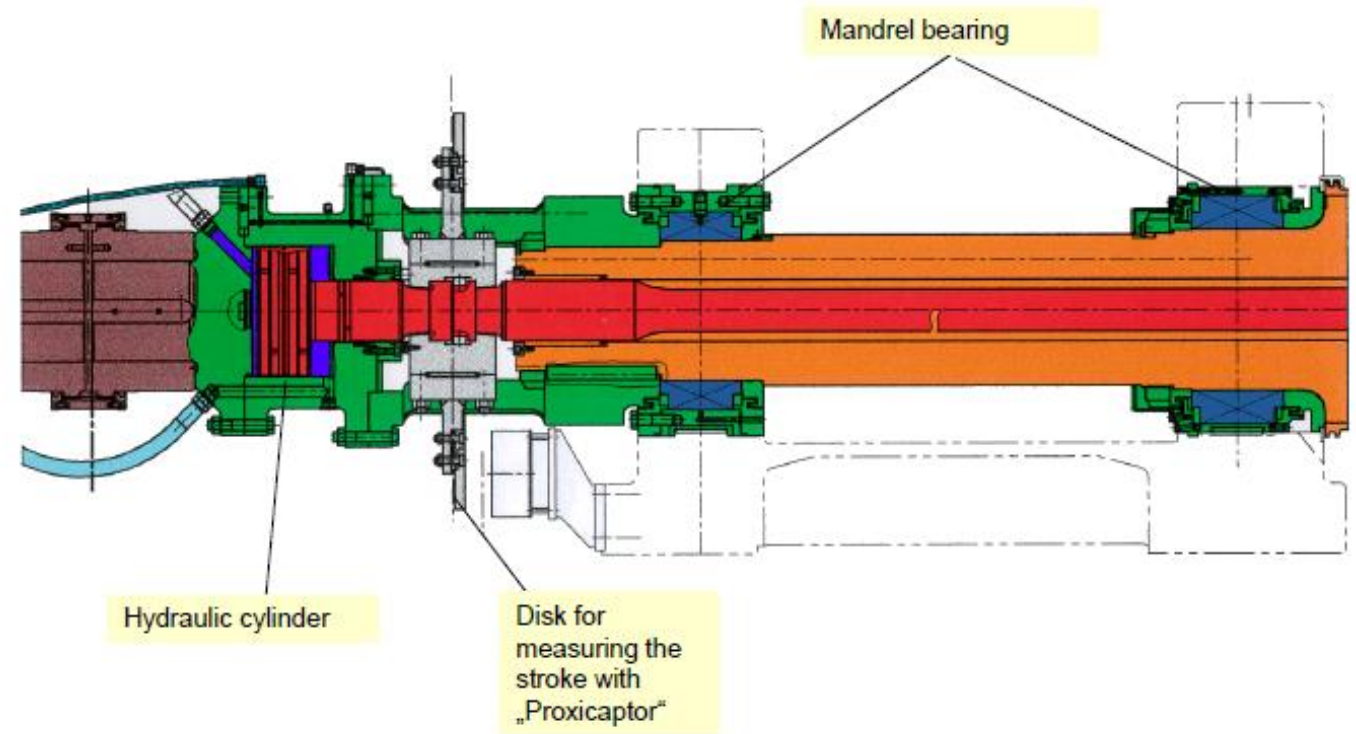

Figura 1. Detalhes do cilindro hidráulico e rolamentos principais de um mandril a quente.

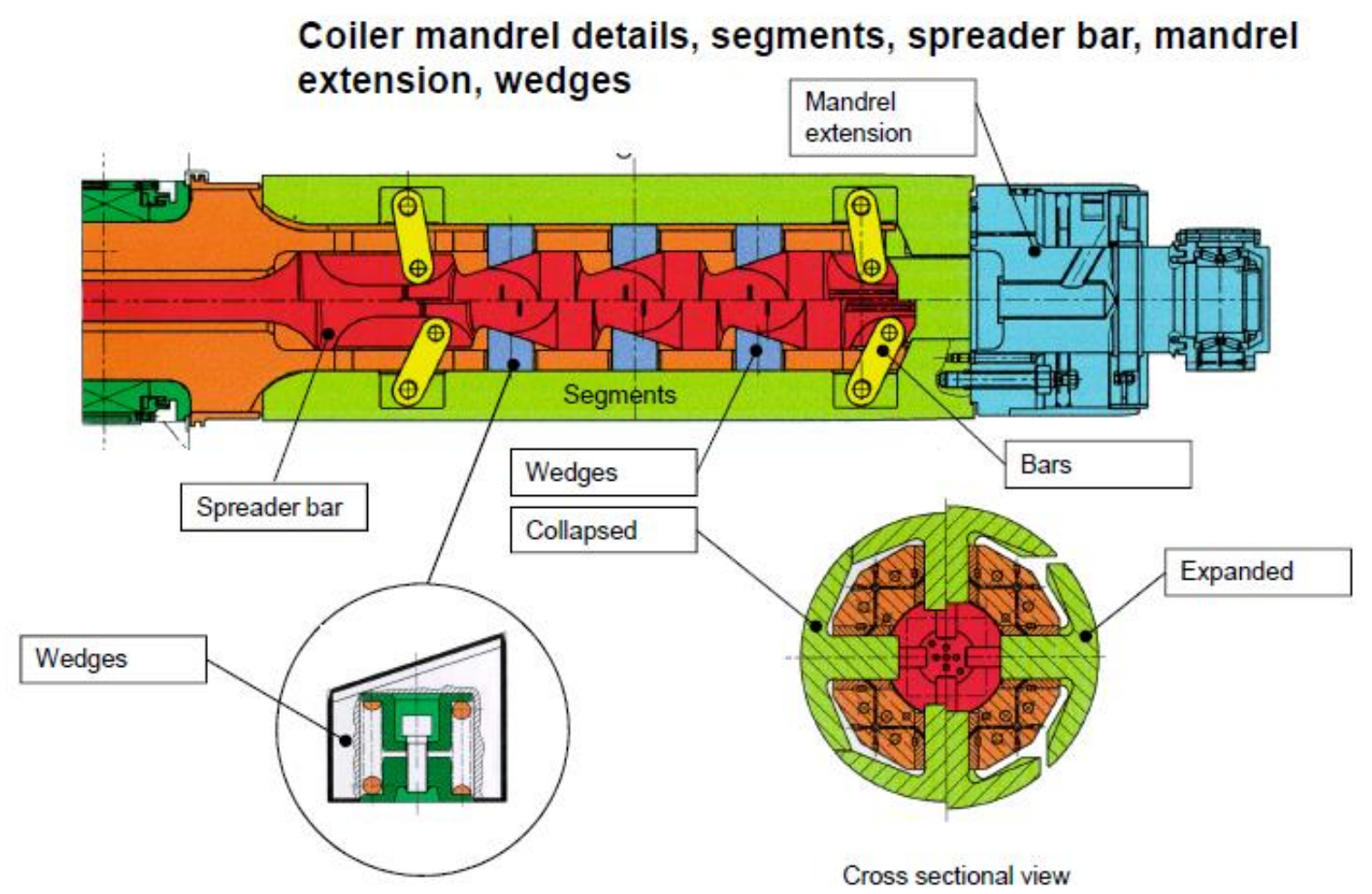

Figura 2. Detalhes dos Segmentos, Piramidal e Cunhas de um mandril a quente. 


\subsubsection{Laminação a frio}

Para laminação a frio temos dois tipos principais de Mandril, sendo o primeiro um Mandril com eixo principal deslocando na axial para acionamento das rampas e consequente expansão/colapso dos Segmentos e o segundo um Mandril onde temos dentro do eixo principal uma haste que desloca uma luva expansora e esta última promove a expansão/colapso os Segmentos. Para os Mandris de saída (bobinadeira) podemos ter o uso de gripper para início do bobinamento. As figuras 3 e 4 mostram desenhos esquemáticos de conjunto desses mandris.
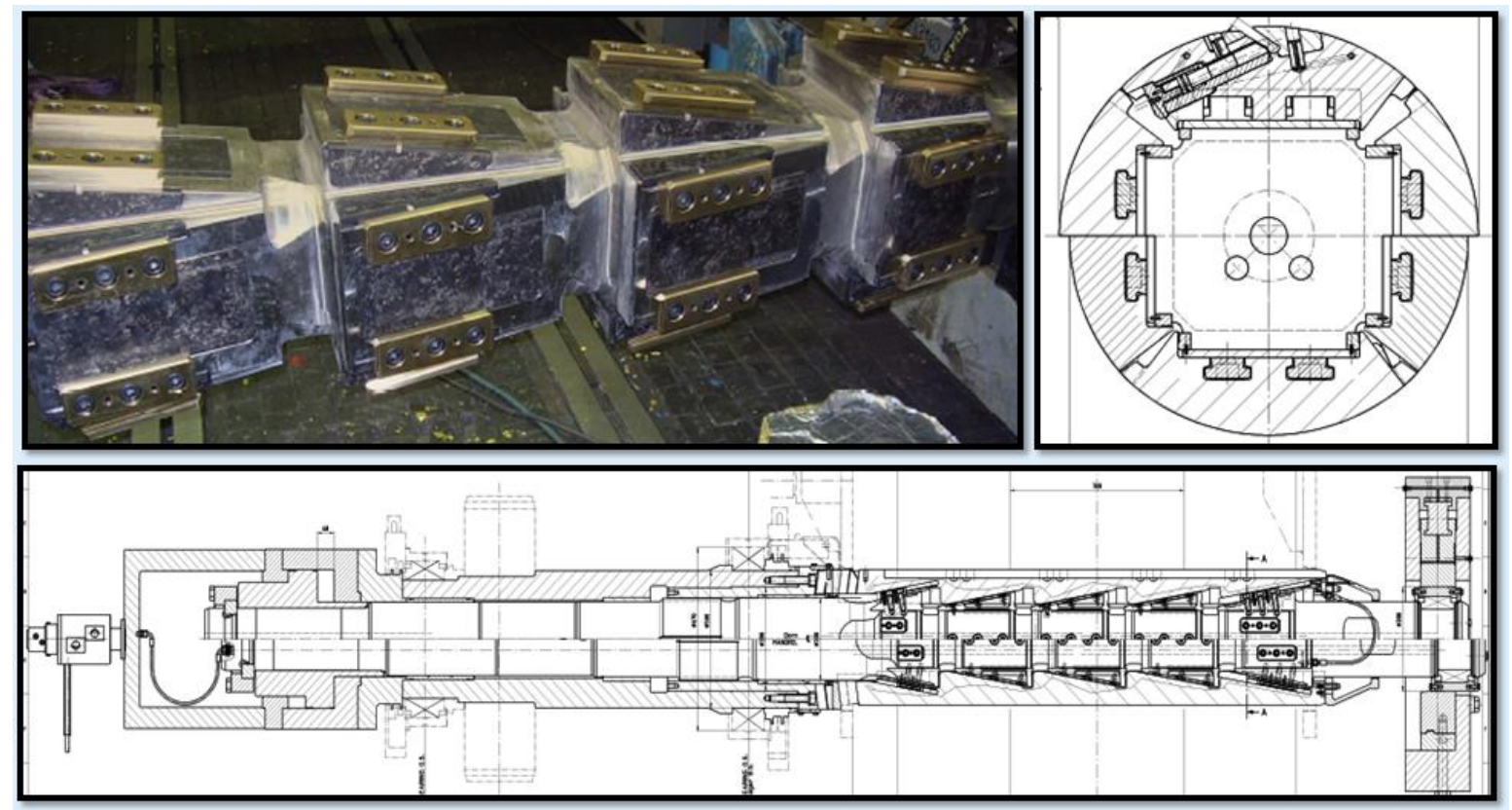

Figura 3. Desenho de conjunto de um mandril a frio com acionamento via Eixo principal.

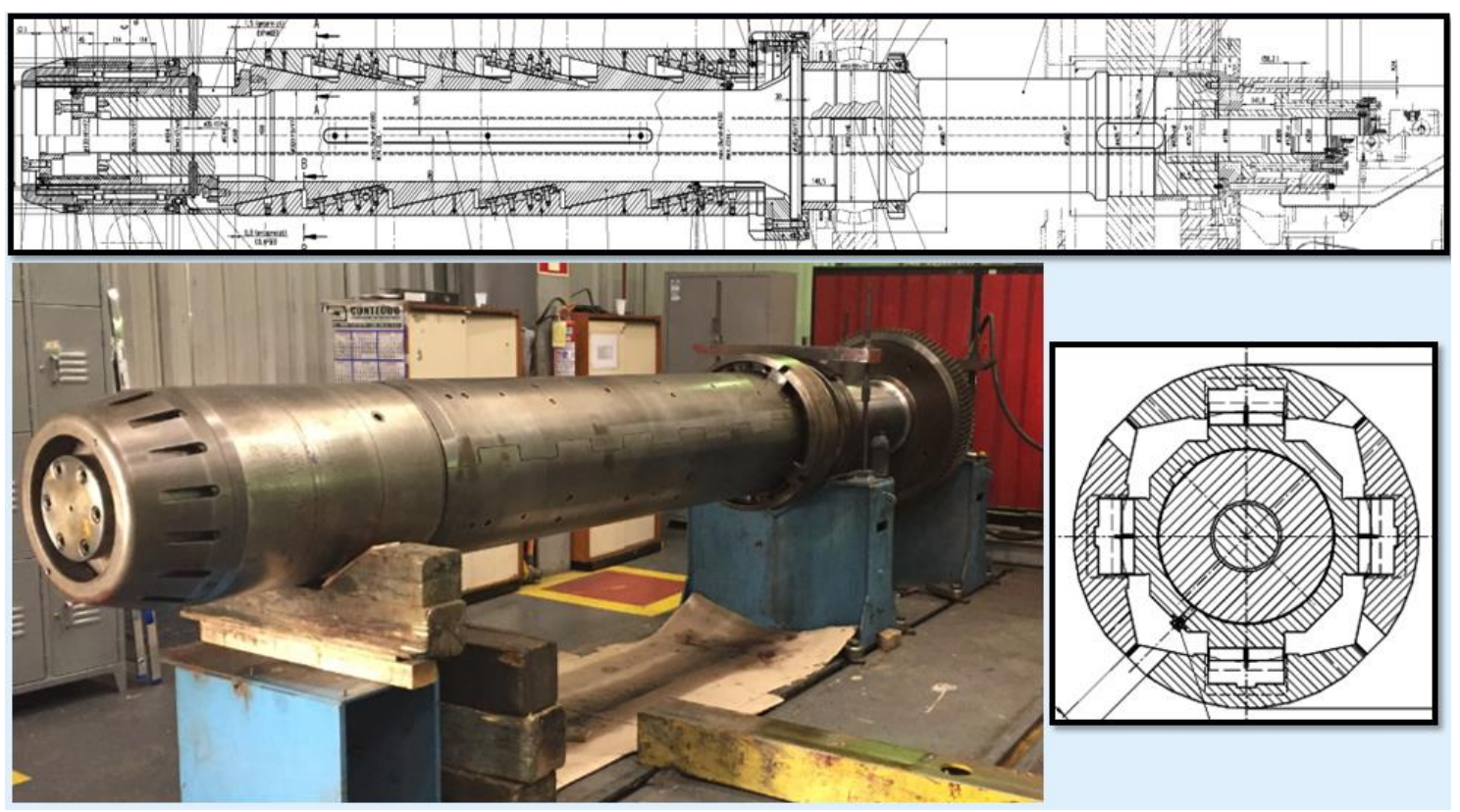

Figura 4. Desenho de conjunto de um mandril a frio com acionamento via Haste e Luva expansora. 


\subsubsection{Linhas de processo}

Como são menos solicitados comparados aos Mandris de laminação a frio, a concepção mais usada é de um Mandril onde temos dentro do eixo principal uma haste para acionamento da luva expansora e Segmentos. Para este tipo de Mandril as rampas possuem ângulos maiores, devido às pequenas cargas às quais são solicitados, tendo assim a característica de pequenos mandris e consequentemente mais baratos. As figuras 5 e 6 mostram desenhos esquemáticos de conjunto desses mandris.

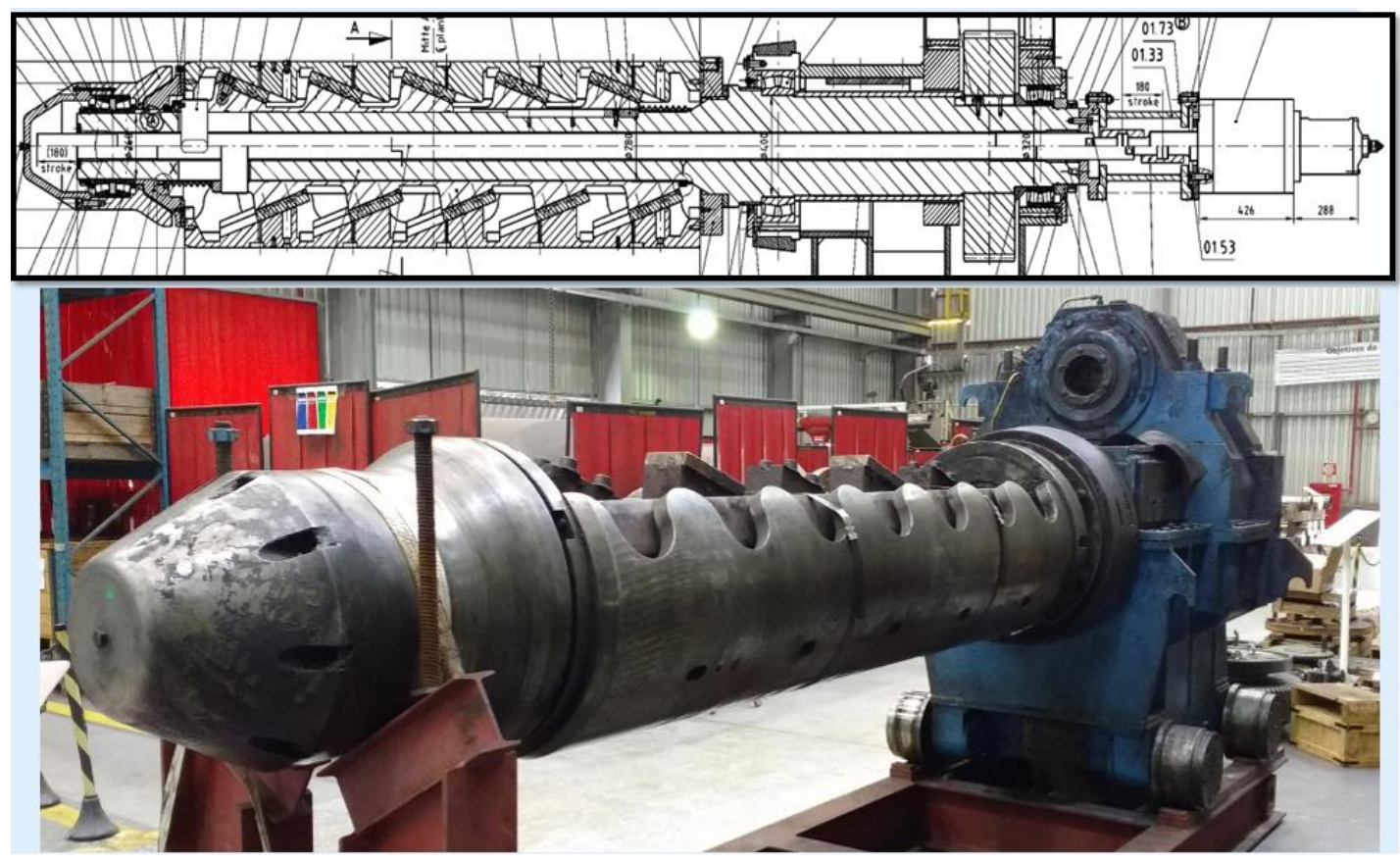

Figura 5. Desenho de conjunto de um mandril da linha de decapagem.
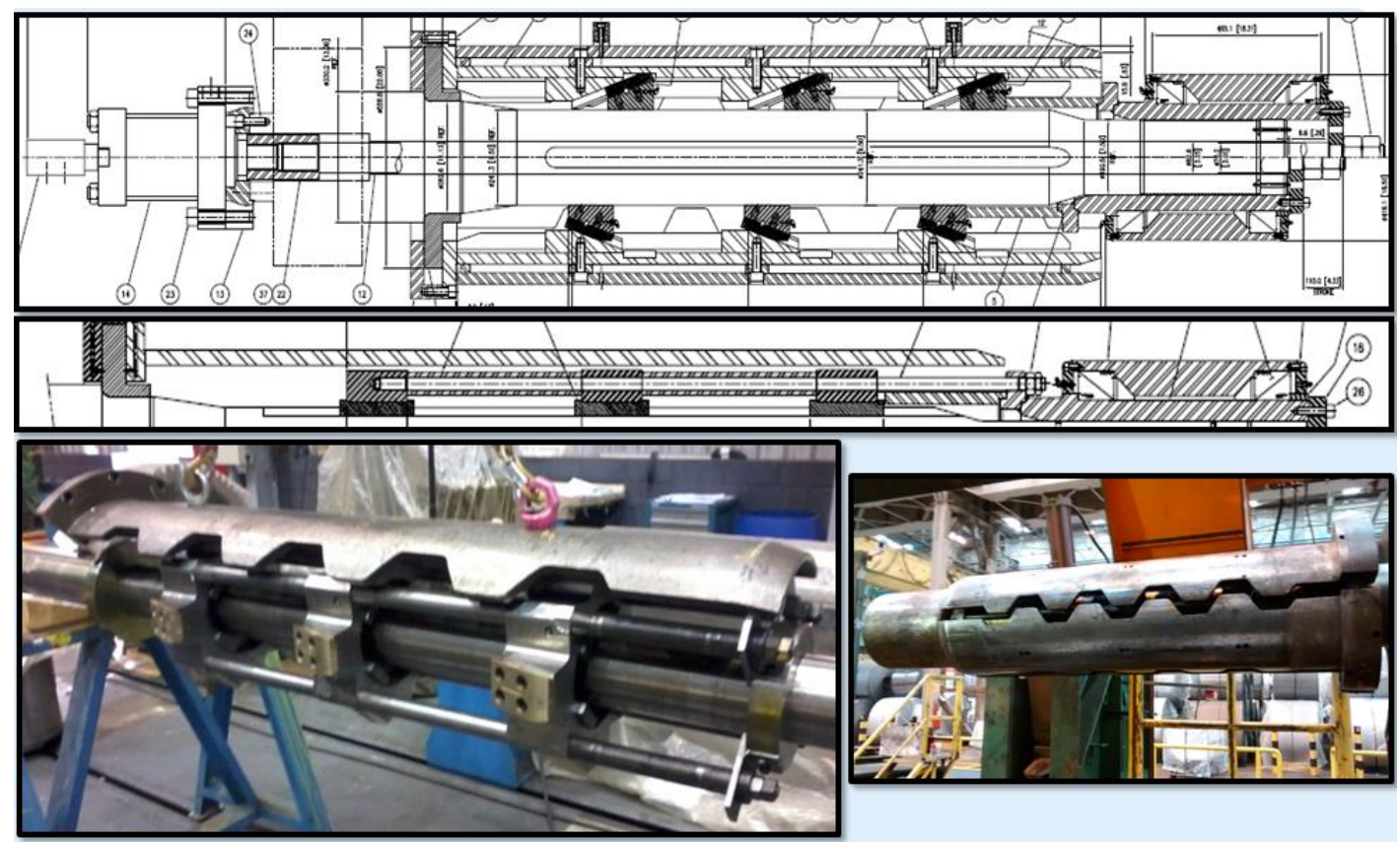

Figura 6. Desenho de conjunto de mandril para linha de galvanização e pintura. 


\subsection{Reengenharia e projeto de Mandris}

Entre os diversos componentes de um mandril, os mais críticos têm um tratamento diferenciado quando do projeto, fabricação e reparo. Alguns exemplos como eixo principal, Segmentos, Luva expansora e partes que possuem rampas são os primeiros componentes a ter total atenção. Para esses componentes, as máquinas identificadas na figura 7 são utilizadas para garantir o perfeito alinhamento, perpendicularismo e controle angular entre as faces inclinadas.
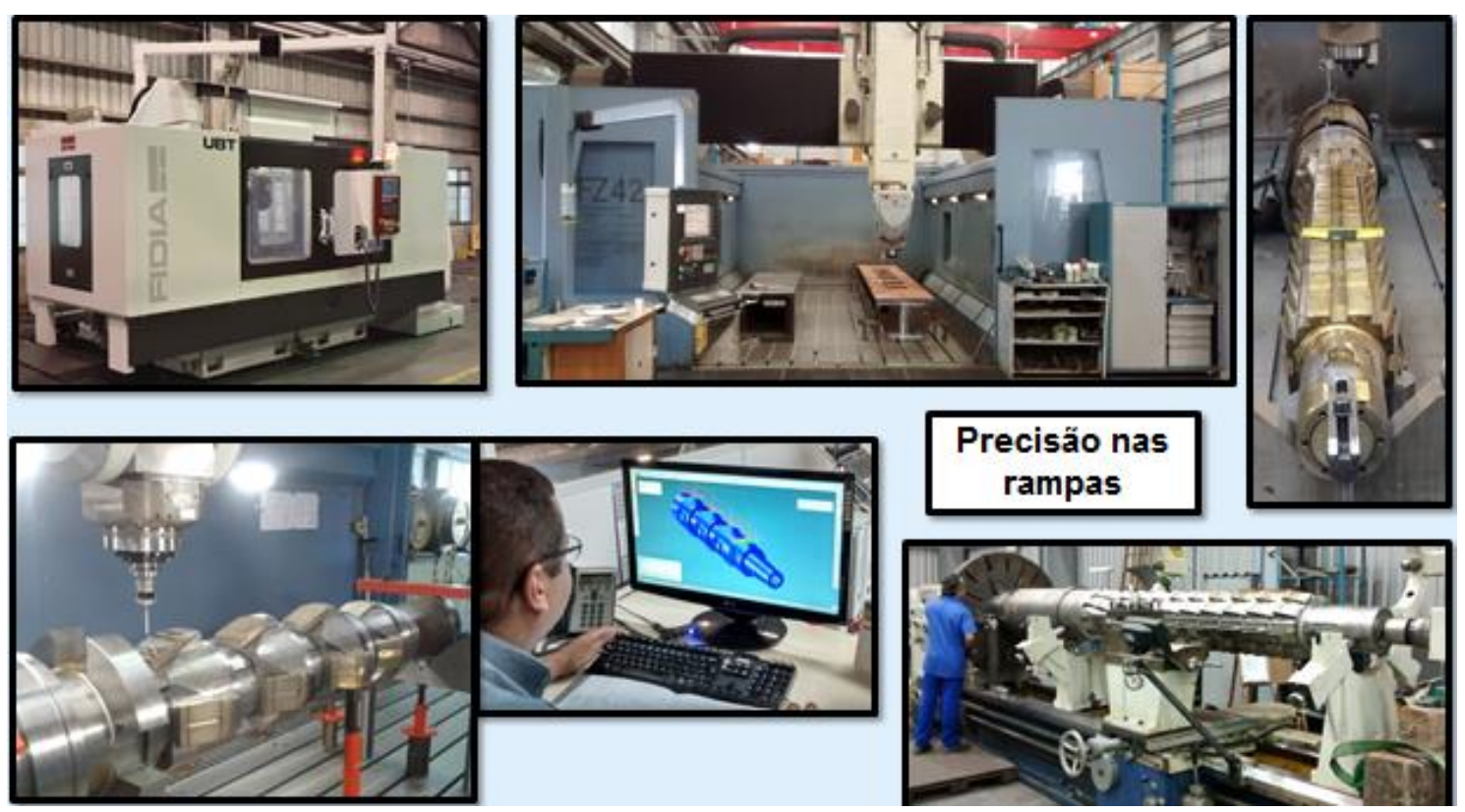

Figura 7. Máquinas para fabricação de equipamentos críticos.

Para o trabalho de reengenharia, após a desmontagem de todos os componentes, tem-se a inspeção destes itens do mandril. Para isso, além de todos os métodos convencionais de medição como micrometro, altímetro, rugosimetro, entre outros, também são utilizados os equipamentos de medição tridimensional e scanner que permitem visualizar todos as características das peças além de coletar o dimensional geral. Esta etapa e um trabalho em conjunto com a equipe de engenharia com a aplicação do know how em Mandris permite além da reengenharia das partes, propor ainda melhorias e aplicação de novas tecnologias, como revestimentos e novos materiais, agregando uma maior performance ao conjunto final. A figura 8 mostra alguns dos equipamentos utilizados no trabalho de reengenharia. 

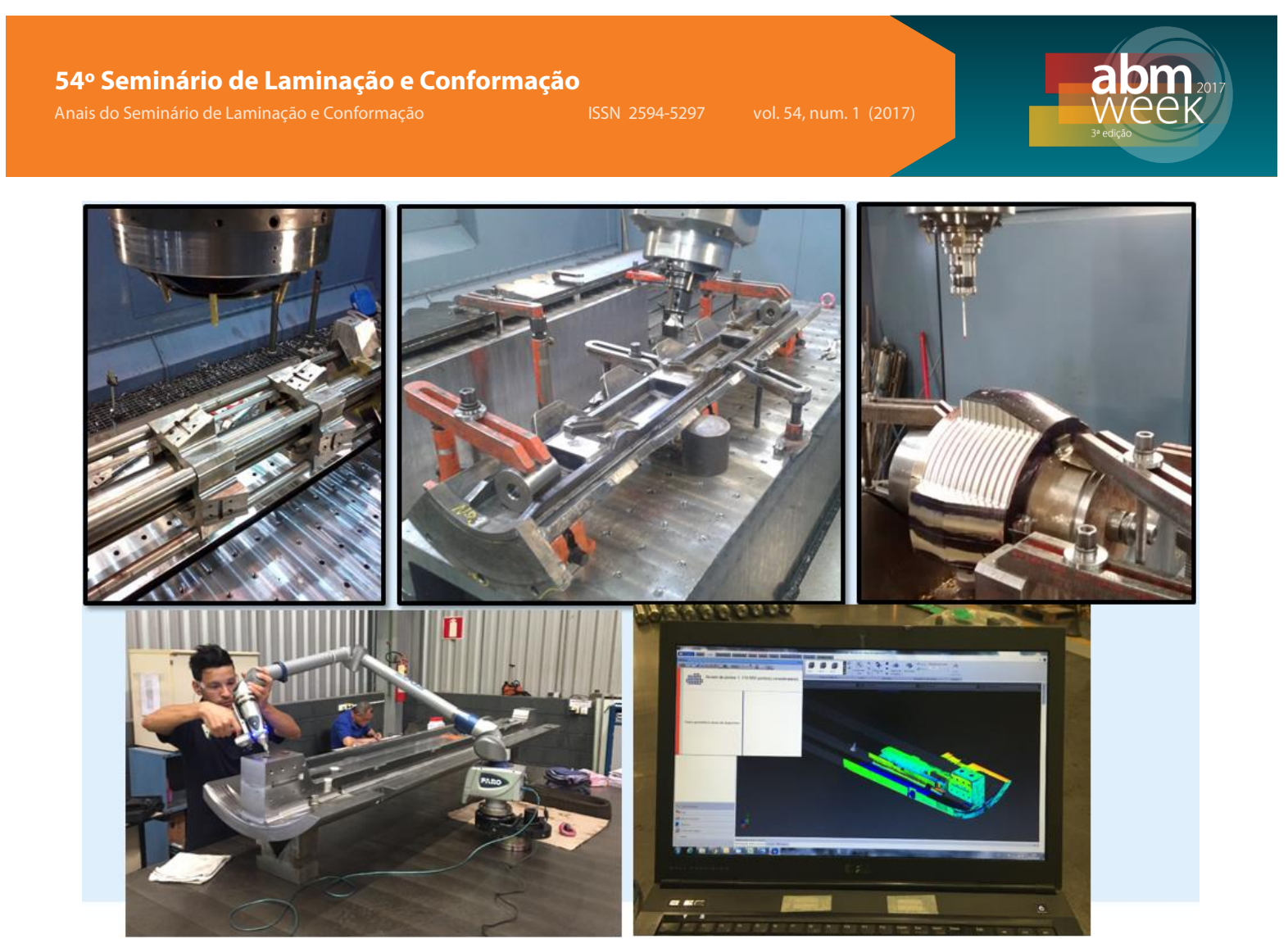

Figura 8. Equipamentos de inspeção tridimensional e scanner.

O último trabalho de reengenharia realizado pela SMS está demonstrado abaixo, com detalhamento de todos os componentes após o modelamento 3D em Creo parametric. Neste trabalho em um Mandril de bobinadiera para Laminação a quente também foram aplicadas várias melhorias em revestimentos e novos materiais de desgaste em pontos estratégicos.
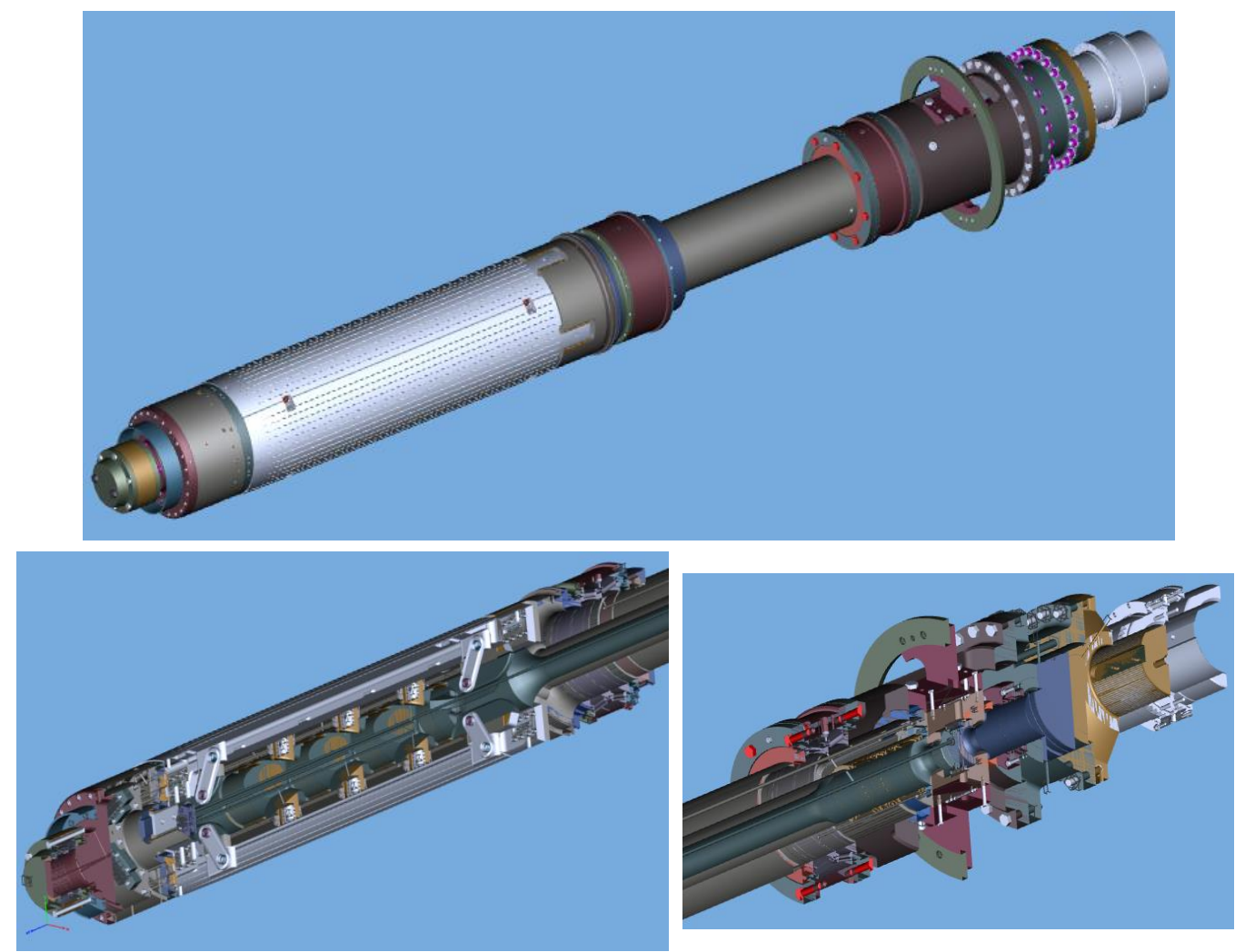

Figura 9. Reengenharia em um Mandril de bobinadeira para Laminação a quente. 


\section{CONCLUSÃO}

Considerando a atual situação do mercado, principalmente pela globalização, vê-se a necessidade de estar sempre atento a renovação dos projetos oferecendo ao cliente a utilização de novas tecnologias, objetivando sempre o aumento de performance do equipamento. Para tanto precisa-se aliar a renovação com menores custos de produção, resultando assim na viabilização da aplicação do projeto.

\section{Agradecimentos}

À SMS Group pela oportunidade de desenvolvimento em todas as áreas da Siderurgia e no contexto deste trabalho por todos os treinamentos e compartilhamento de know how em Mandris. 